\title{
Correction to: Two Novel Acetylesterases from Pantoea dispersa: Recombinant Expression, Purification, and Characterization
}

\section{Damaris Batistão Martim ${ }^{1} \cdot$ Ione Parra Barbosa-Tessmann ${ }^{1}$}

Published online: 3 July 2019

C) Springer Science+Business Media, LLC, part of Springer Nature 2019

\section{Correction to: Applied Biochemistry and Biotechnology https://doi.org/10.1007/s12010-019-03024-y}

The original version of this article unfortunately contained a mistake. Under Materials and Methods heading, Bacterial Strains sub-heading, the correct name of the used strain is "FEI4 65 " and not "FzEI4 65."

The original article has been corrected.

The original version of this article unfortunately contained a mistake in the images of Figs. 1 and 6 . The corrected version of the figures is shown here.

The authors' apologizes for the oversight and for any confusion it may have caused.

The online version of the original article can be found at https://doi.org/10.1007/s12010-019-03024-y

Ione Parra Barbosa-Tessmann ipbtessmann@uem.br

Damaris Batistão Martim damaris.martim@hotmail.com

1 Department of Biochemistry, State University of Maringá, Av. Colombo, 5790, Maringá, PR 

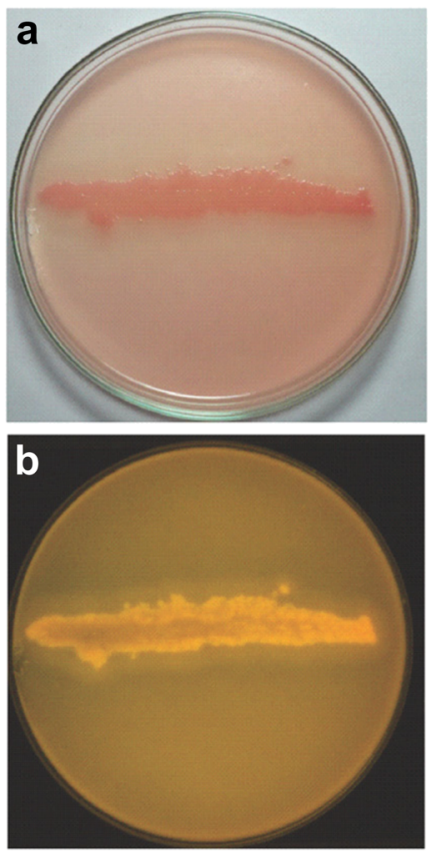

C

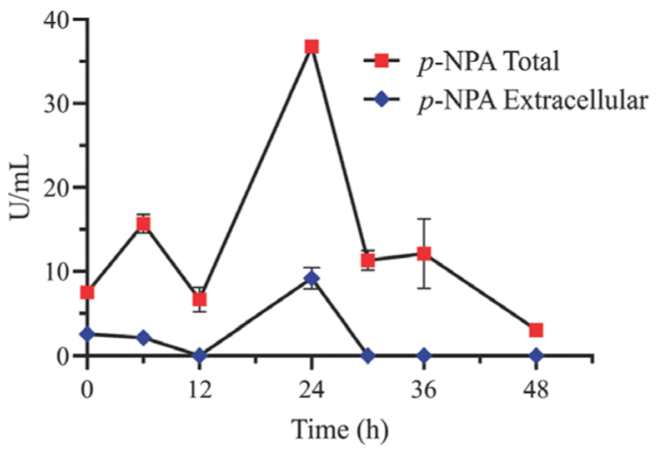

e
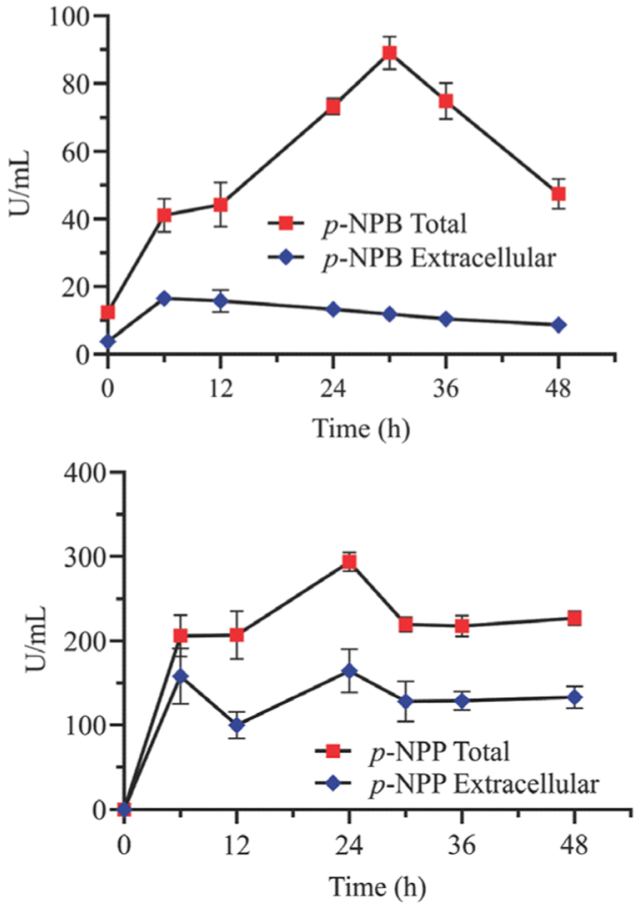

Fig. 1 Expression profile of lipolytic enzymes by $P$. dispersa. a A Petri dish containing $P$. dispersa cultured in Rhodamine B medium (front). b The same culture of $P$. dispers $a$ in Rhodamine B medium photographed under UV light (reverse). Total (cell-bound + extracellular) and extracellular expression profile of acetylesterase (c), butyryl esterase (d), and lipase (e), assayed with $p$-NPA, $p$-NPB, and $p$-NPP, respectively, in a 10-min enzyme reaction. The data represents the average and standard deviation of the results obtained in three culture flasks 
a

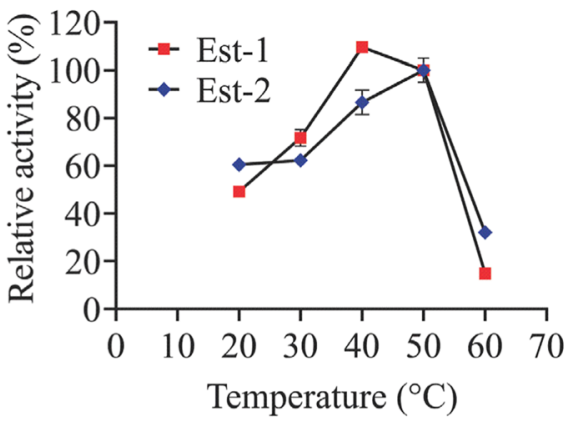

b

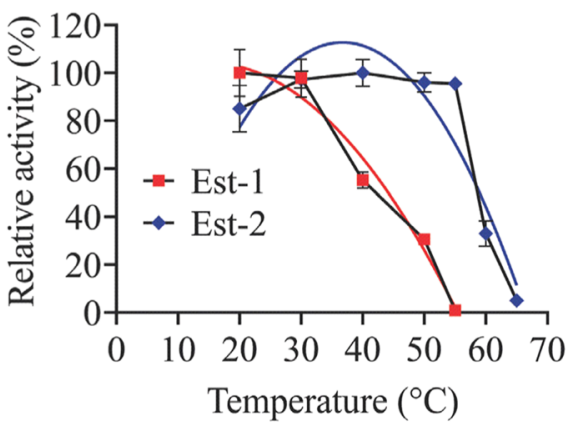

C

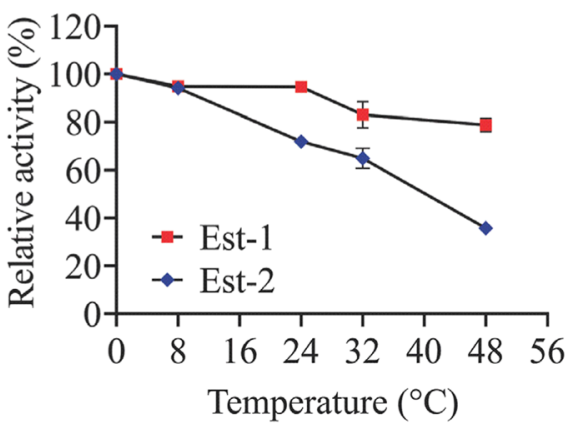

d

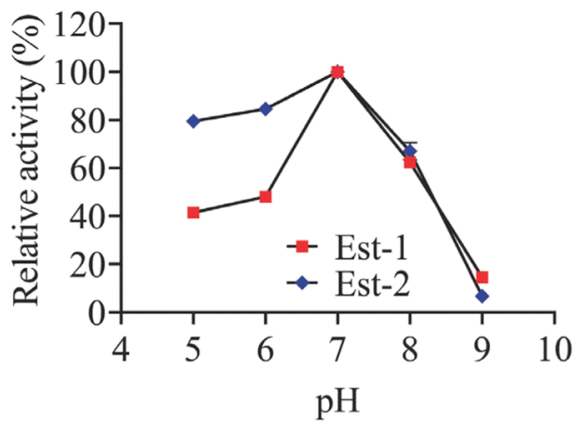

e

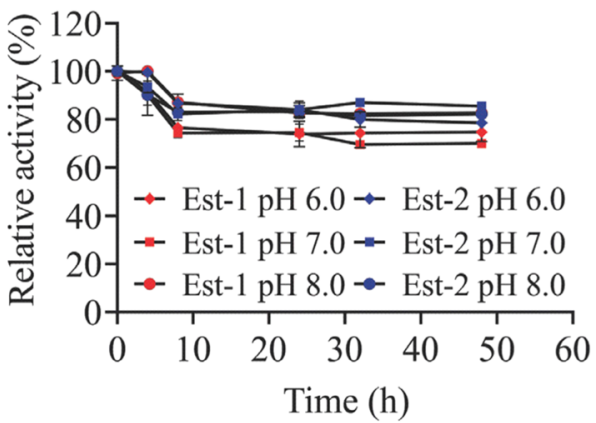

f

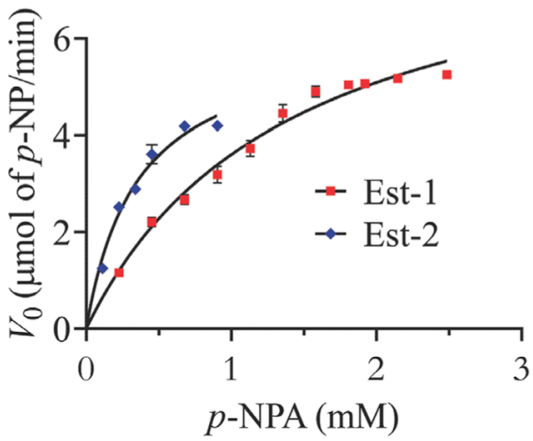

Fig. 6 Biochemical parameters of $P$. dispers $a$ Est- 1 and Est-2. a Optimal temperatures. b Thermal stabilities. The second order polynomial regression curves are indicated in colors. c Temperature stability time courses. d Optimal pHs. e pH stability time courses at $4{ }^{\circ} \mathrm{C}$. f Saturation curves. The data represents the average and standard deviation of three experimental sets

Publisher's Note Springer Nature remains neutral with regard to jurisdictional claims in published maps and institutional affiliations. 